\title{
Determination of the Effect of Soil Particle Size Distribution on the Shear Behavior of SAND
}

\author{
Mohammad AFRAZI $I^{1, *}$, Mahmoud YAZDANI ${ }^{1}$ \\ ${ }^{1}$ School of Civil and Environmental Engineering, Tarbiat Modares University, Tehran, Iran \\ *Corresponding Author: Mohammad AFRAZI (Email: Mohammad.afrazi@modares.ac.ir) \\ (Received: 1-Jun-2021; accepted: 12-Jun-2021; published: 30-Jun-2021) \\ DOI: http://dx.doi.org/10.25073/jaec.202152.331
}

\begin{abstract}
Many geotechnical problems require the determination of soil engineering properties such as shear strength. Therefore, the determination of the reliable values for this parameter is essential. For this purpose, the direct shear test, as one of the oldest tests to examine the shear strength of soils, is the most common way in laboratories to determine the shear parameters of soil. There are far too many variables that influence the results of a direct shear test. In this paper, a series of $10 \times 10 \mathrm{~cm}$ direct shear tests were carried out on four different poorly graded sands with different particle size distributions to determine their shear behaviors. Four different poorly graded sands with a different median diameter or medium value of particle size distribution $\left(D_{50}\right)(0.2,0.53,1.3$, and $2.3 \mathrm{~mm})$ has been selected, and about 40 direct shear tests were conducted. It was concluded that a soil's friction angle is affected by coarse-grained material. Accordingly, sandy soils with bigger particle sizes record a higher friction angle than soils containing small particles. The investigations also showed that sand with bigger particle sizes has a higher dilation angle. In addition, a non-linear regression analysis was performed to establish the exact relationship between the friction angle of the soil and the characteristics of the soil particles.
\end{abstract}

\section{Keywords}

Direct shear test, particle size distribution, sand, shear strength, dilation angle.

\section{Introduction}

Shear strength of soils is one of the most critical parameters in the geotechnical designs used in analyzing problems such as lateral soil pressure, bearing capacity of foundations, slope stability, earth dams, and other geotechnical problems [1, 2]. Standard tests for measuring soil shear strength include triaxial, direct shear, and simple shear tests. The non-uniformity of stress and strain in direct shear test, predefined failure plane, and having rigid boundary condition are three major disadvantages of direct shear tests. However, among those, the direct shear test is still the most common test due to its wide application in understanding the mechanical behavior of soils [3-5] since the direct shear test takes less time to fail and complete than the triaxial test and simple shear test $[1,6,7]$. Recently, considerable literature has grown around the shear strength characteristics of sands and sand-gravel mixtures [8-16]. The academic literature on their shear strength has revealed the emergence of several contrasting themes. The shear strength of sand is primarily controlled by its gradation curve, according to these studies. 
A few of these researches have shown the reduction of shear strength with increasing the median diameter or medium value of particle size distribution $\left(D_{50}\right)$ [8-10]. On the other hand, others have reported an increase in shear strength as the $D_{50}$ of sands increases [11-14]. There are also a number of other observations on the shear strength characteristics of sandy gravels or gravely sands that indicate the significant impact of soil gradation on mechanical behavior [17-24].

A large number of cross-sectional studies have found a relation between $D_{50}$ as well as sand shear strength. According to Fragaszy et al. (1990) [8], increasing $D_{50}$ increases the void ratio of the soil matrix, decreasing the fiction angle and dilation angle of soils. Unlike Fragaszy et al. (1990), Yagiz (2001) [11] argues that the shape and content of gravel particles have a major impact on the friction angle of the mixture, and increasing $D_{50}$ increases the shear strength of soils. Similarly, Simoni and Houlsby (2006) [25] have observed the same findings. Simoni and Houlsby (2006) conducted 87 large direct shear tests on sand-gravel mixtures of different $D_{50} \mathrm{~s}$ and came to the conclusion that increasing $D_{50}$ would increase the dilatancy rate and the critical state friction angle.

Salimi et al. (2008) [26] investigated the effect of particles' sizes and shapes of two different gravel on the shear strength of sand-gravel mixtures in low gravel contents of loose mixtures and reached the conclusion that the form and size of the particles have only a minor impact on the shear strength and friction angle of soils. When the $D_{50}$ increases, though, it becomes more apparent. Hamidi et al. (2009) [14] used a large-scale direct shear apparatus with a $30 \mathrm{~cm} \times 30 \mathrm{~cm} \times 17 \mathrm{~cm}$ shear box to study the shear strength of sandy soils with different $D_{50} \mathrm{~s}$. To do so, they performed a series of direct shear tests on sand-gravel soils comprising 20, 40, and 60 percent gravel. All of the experiments were carried out on dry samples in drained conditions. Three different densities of 35, 60, and 85 percent were included in the experiments, as well as three different normal stresses of 150 , 300 , and $450 \frac{\mathrm{kN}}{\mathrm{m}^{2}}$. They discovered that increasing the $D_{50}$ and relative density causes the shear strength and dilation of the mixture to increase.
The $D_{50}$, on the other hand, has a more noticeable impact on shear strength than on relative density. In another investigation, Hamidi et al. (2012) [27] studied the shear strength and dilatancy of well-graded sand-gravel mixtures by conducting 27 large-scale direct shear tests and reported that the particle size distribution and $D_{50}$ of the tested soils significantly affect their shear strength. In a comprehensive study of the impact of $D_{50}$ on the shear behavior of soils, Rasti et al. (2021) [28] performed a series of direct shear tests on four different sands and found that the $D_{50}$ of soils affects their critical friction angle.

The studies presented thus far provide evidence that particle size distribution of sands has an essential effect on their shear behaviors $[29,30]$. Considering all of this evidence, however, the impact of $D_{50}$ on the shear behavior of poorly graded sands received little attention. The purpose of this investigation is to explore the relationship between the shear behavior of poorly graded sand (Based on the ASTM D248717) and $D_{50}$. To do so, 40 direct shear tests were performed on the four different poorly graded sand with different $D_{50} \mathrm{~s}$. This paper has been divided into three parts. The first part deals with materials and testing programs, the second part discusses the impact of $D_{50}$ on the shear strength behavior of sands, while the last part discusses the deformation behavior of soils.

\section{Materials and testing program}

\subsection{Sand}

Four different sands with different particle size distributions (Based on ASTM D6913-04) were collected from Tehran and were used in this study. The sand particles were sieved, and their particle size distribution is shown in Fig. 1. As can be seen from Fig. 1, the $D_{50}$ of materials are estimated and ranged between $0.2 \mathrm{~mm}$ and $2.3 \mathrm{~mm}$. The index properties of sands are presented in Tab. 1. 
Tab. 1: Typical engineering properties of soil samples. ${ }^{*} C_{U}=\frac{D_{60}}{D_{10}},{ }^{* *} C_{C}=\frac{D_{30}^{2}}{D_{60} D_{10}}$.

\begin{tabular}{|l|l|l|l|l|l|l|l|l|l|}
\hline $\begin{array}{l}\text { Sample } \\
\text { ID }\end{array}$ & Soil name & $\begin{array}{l}\text { Soil } \\
\text { symbol }\end{array}$ & $\begin{array}{l}D_{10} \\
(\mathrm{~mm})\end{array}$ & $\begin{array}{l}D_{30} \\
(\mathrm{~mm})\end{array}$ & $\begin{array}{l}D_{50} \\
(\mathrm{~mm})\end{array}$ & $\begin{array}{l}D_{60} \\
(\mathrm{~mm})\end{array}$ & ${ }^{*} C_{U}$ & ${ }^{* *} C_{C}$ & $\begin{array}{l}\text { Max. } \\
\text { Particle } \\
\text { size (mm) }\end{array}$ \\
\hline Soil \#1 & $\begin{array}{l}\text { Poorly } \\
\text { graded sand }\end{array}$ & SP & 0.14 & 0.19 & 0.25 & 0.28 & 2.00 & 0.92 & $>5$ \\
\hline Soil \#2 & $\begin{array}{l}\text { Poorly } \\
\text { graded sand }\end{array}$ & SP & 0.26 & 0.38 & 0.53 & 0.60 & 2.30 & 0.92 & $>2$ \\
\hline Soil \#3 & $\begin{array}{l}\text { Poorly } \\
\text { graded sand }\end{array}$ & SP & 0.91 & 1.08 & 1.30 & 1.41 & 1.55 & 0.90 & $>2$ \\
\hline Soil \#4 & $\begin{array}{l}\text { Poorly } \\
\text { graded sand }\end{array}$ & SP & 1.01 & 1.57 & 2.30 & 2.67 & 2.64 & 0.91 & $>0.9$ \\
\hline
\end{tabular}

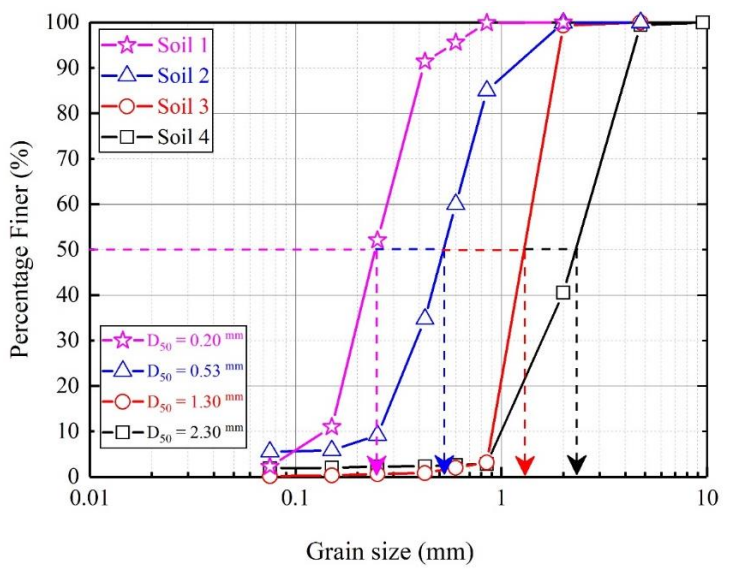

Fig. 1: Particle size distributions of used materials.

\subsection{Sample preparation and testing program}

Direct shear tests were conducted using the Azmoon Company apparatus. The size of the shear box is $100 \mathrm{~mm}$ by $100 \mathrm{~mm}$, and its height is $35 \mathrm{~mm}$ as shown in Fig. 2. All of the samples were made in three successive layers in dry conditions. Each layer was compacted to achieve the required density of $1.6 \mathrm{gr} / \mathrm{cm}^{3}$. All of direct shear tests were conducted based on the American Society for Testing and Materials (ASTM) standard (ASTM D3080) at a constant and low displacement speed of $0.5 \mathrm{~mm} / \mathrm{min}$ under three different normal stresses of 60,120 , and $180 \mathrm{kPa}$ to estimate the shearing response of materials.

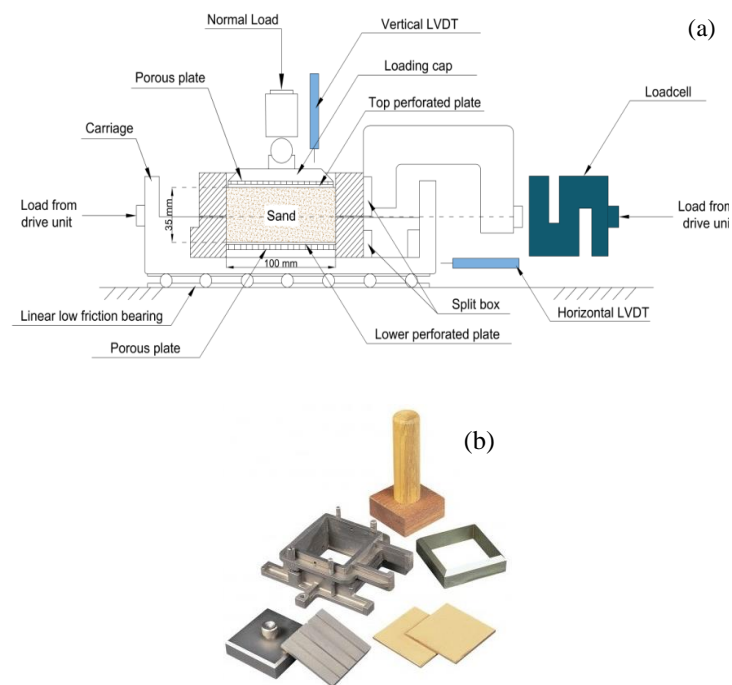

Fig. 2: (a) A sketch of the shear box used for the experimental tests; (b) Direct shear box container.

\section{Results and discussion}

\subsection{Repeatability}

Three tests were performed under the same conditions on each sample to assure repeatability of the results. Considering this fact, together with application of four different sand and three different normal stresses of $60 \mathrm{kPa}, 120 \mathrm{kPa}$, and $180 \mathrm{kPa}$, more than 36 direct shear tests were conducted. Figure 3 shows the shear and deformation behavior of sand 3 under $120 \mathrm{kPa}$ normal stress. As shown in the below figure, the results 
can be reasonably well reproduced. Therefore, the averaged data are used to report the results in the following sections of the paper.
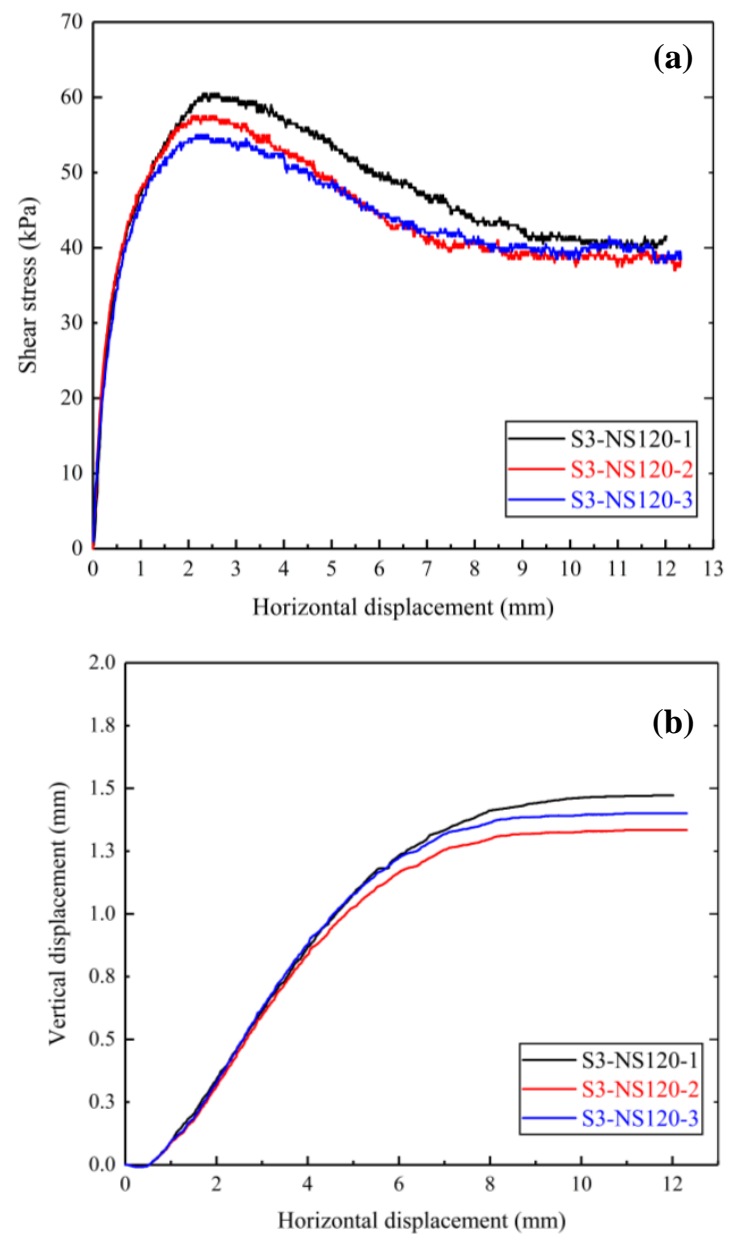

Fig. 3: (a) Shear stress-Shear displacement; (b) Vertical displacement-Shear displacement of sand 3 under $120 \mathrm{kPa}$ normal stress. S and NS stand for the Sand and Normal Stress, respectively.

\subsection{Shear strength}

Shear strength behavior of sands with different $D_{50}$ of $0.20,0.53,1.30$, and $2.30 \mathrm{~mm}$ are presented in the following figures. Figure 4 illustrates the shear strength behavior of sands under three different normal stresses. The results show the well-predicted behavior of samples which consist of strain hardening of sand samples followed by strain-softening toward the critical state under the applied normal stresses.
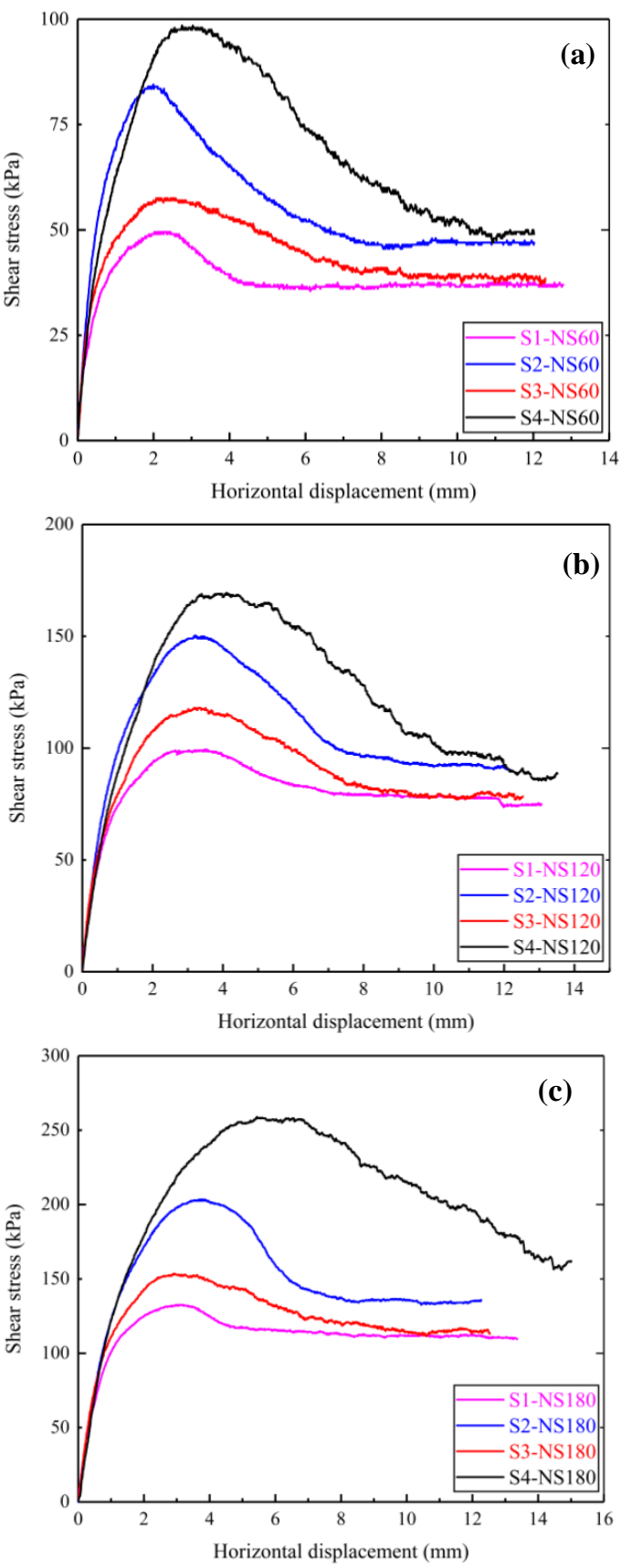

Fig. 4: Shear stress-Shear displacement of sands under normal stresses of (a) $60 \mathrm{kPa}$; (b) $120 \mathrm{kPa}$; (c) $180 \mathrm{kPa}$. S and NS stand for the Sand and Normal Stress, respectively.

From Fig. 4(a, b, c) we can also see that the initial stiffness of sands is consistent with increasing $D_{50}$, while peak shear stresses and that the 
shear displacement corresponding to the shear strength of samples increase. Notice that the effect of $D_{50} \mathrm{~s}$ on stress-displacement behavior of the samples is more significant under normal stresses of $120 \mathrm{kPa}$ and $180 \mathrm{kPa}$ compared to those under $60 \mathrm{kPa}$ normal stress. This finding was also reported by Yagiz (2001) [11]. The impact of normal stress on the peak shear strengths and friction angles of the samples is shown in Fig. 5(a, b).
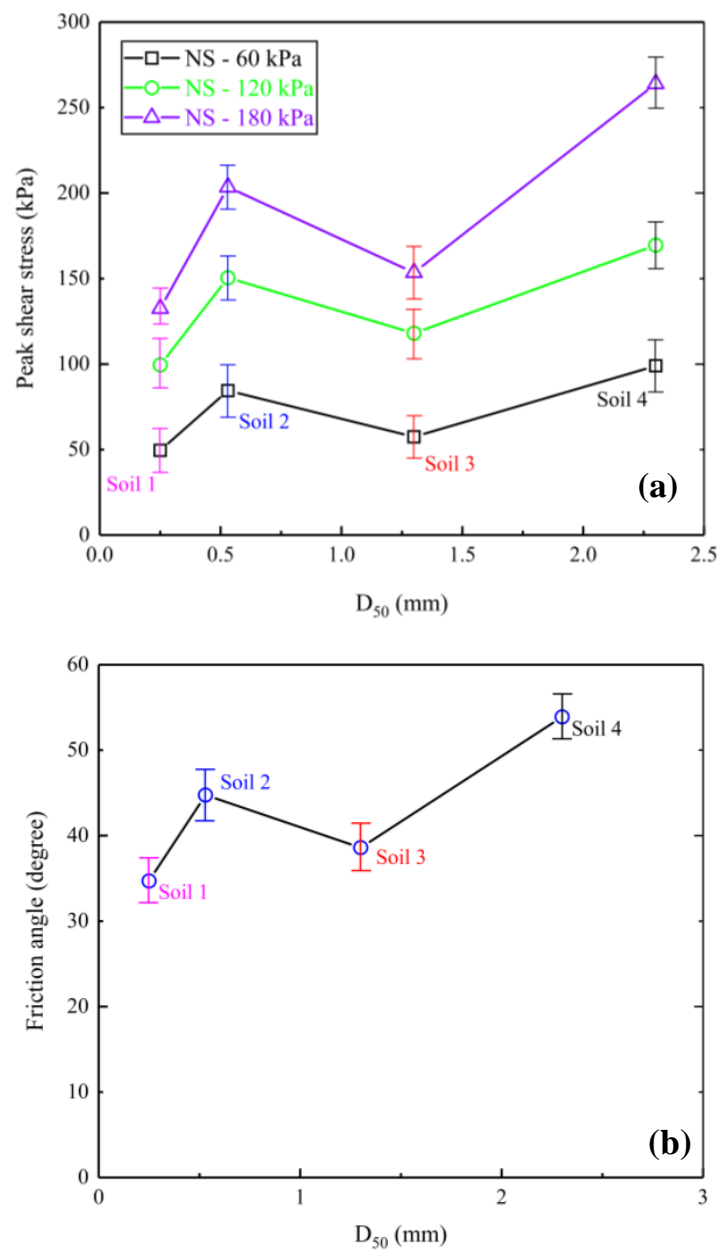

Fig. 5: Effect of $D_{50}$ on: (a) Peak shear stress; (b) Friction angle of sands. NS stands for Normal Stress.

Figure 5(a, b) presents the peak shear strength and friction angle of all samples. It confirms clearly that shear strengths of samples with bigger $D_{50}$ are higher than mixtures with smaller ones; therefore, particle size distri-
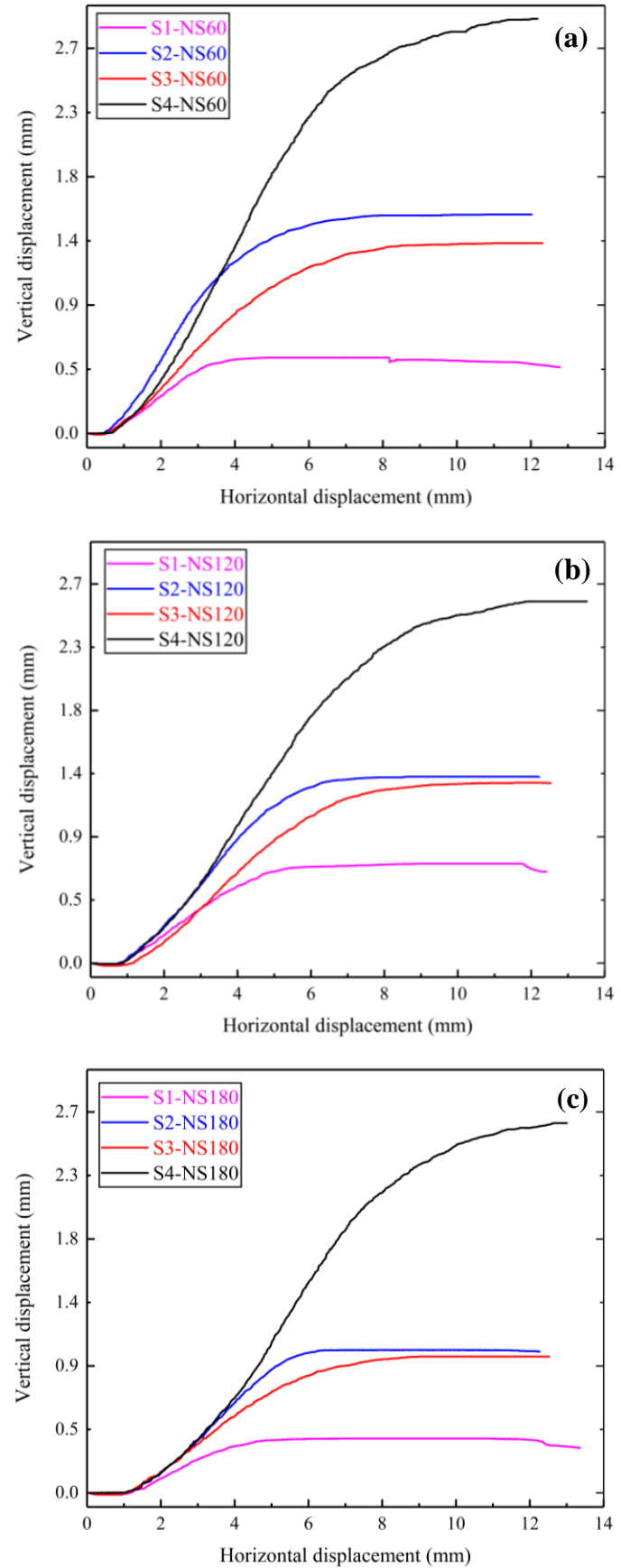

Fig. 6: Vertical displacement-Shear displacement of sands under normal stresses of: (a) $60 \mathrm{kPa}$; (b) $120 \mathrm{kPa}$; (c) $180 \mathrm{kPa}$. S and NS stand for the Sand and Normal Stress, respectively.

butions of sands play a significant role in the shear strength of samples [31]. It is encouraging to compare this figure with that found by 
Rasti et al. (2021) [28], who also found that with increasing $D_{50}$, the peak shear strength of samples increases. One unanticipated finding in Fig. 5(b) is that sand 4 has friction angle of about $50^{\circ}$, however this magnitude is also reported in Bareither et al. (2008) [32], Sladen et al. (1986) [31]. The results in this section indicate that particle size distribution and $D_{50}$ have an important impact on the shear strength of sands. The next section, therefore, moves on to discuss the dilatancy behavior of sands with different particle size distributions.

\subsection{Dilation behavior}

The vertical displacement of samples with different $D_{50} \mathrm{~s}$ are shown in Fig. $6(\mathrm{a}, \mathrm{b}, \mathrm{c})$. Results show the compressive behavior of sands followed by dilative behavior at higher shear displacement. The deformation behavior of sands also shows that the tendency of the samples to dilate increases by increasing the $D_{50}$ s of the samples. These results provide further support for the hypothesis that the overall dilation and deformation behavior of the sands are controlled by their particle size distributions and $D_{50}$ s.

The schematic behavior of sand particles is illustrated in Fig. 7. In fact, when sands have bigger particles and they roll on each other in a direct shear test, they will have bigger vertical displacement and dilation. These results are in agreement with Hamidi et al. (2009) [14] findings that showed increasing $D_{50}$ will increase the dilative behavior of sands.
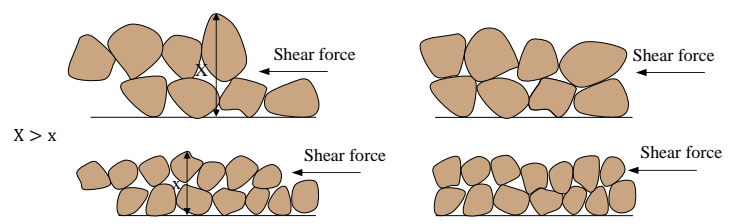

Fig. 7: Schematic view of displacement response, due to the shear loading.

To measure the dilation angle at the peak shear stress, at first, the maximum shear stress was found as in Fig. 8(a), then the displacement corresponding to that point was determined in its vertical displacement diagram (Fig. 8(b)). In the next step, the slope of this point was calcu- lated from Fig. 8(b) and is considered as the dilation angle. The results of the dilation angle are shown in Fig. 9.
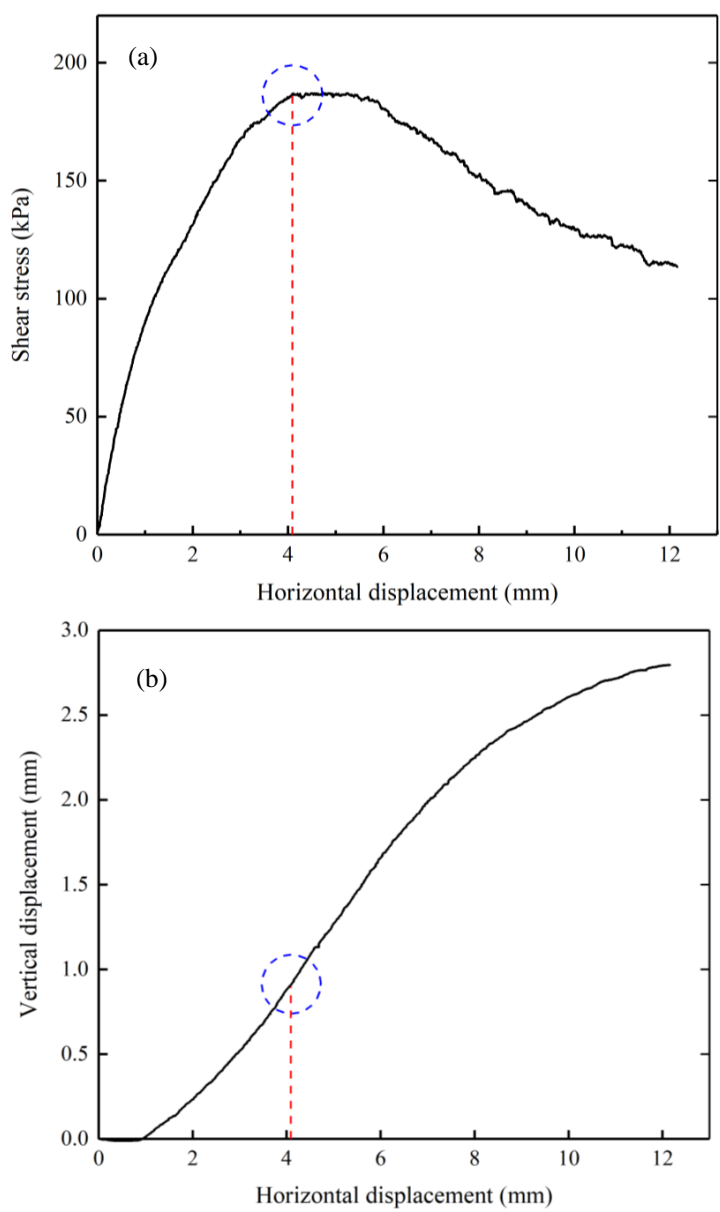

Fig. 8: (a) Shear stress-Shear displacement; (b) Vertical displacement-Horizontal displacement behavior of sand.

The variation of the dilation angle at the peak shear stress in terms of $D_{50}$ s under different normal stresses is shown in Fig. 9. In general, the angle of dilatancy increases by increasing the $D_{50} \mathrm{~s}$ of sands. This is consistent with Fig. 5(b); a material with a higher friction angle shows higher dilatancy under shear [33]. Note that based on Fig. 9, at higher normal stresses, less material dilation is observed, which should be expected.

In Fig. 10, the friction angle of sands versus the dilation angle (for three normal stresses of 60,120 , and $180 \mathrm{kPa}$ ) is shown. Notice the 


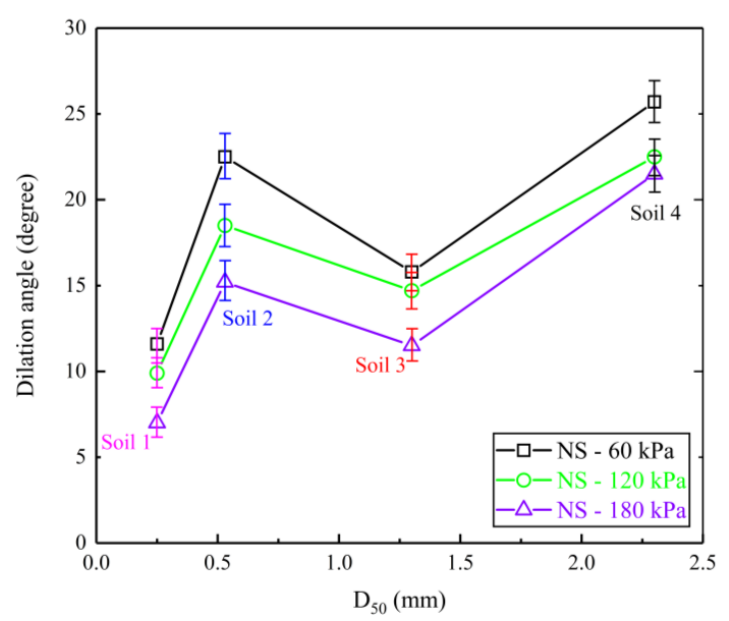

Fig. 9: Effect of $D_{50}$ on dilatancy of sands at different normal stresses.

friction angle increases as the dilation angle and $D_{50}$ increase, which is consistent with the observations of soil behavior reported in the literature [31-35].

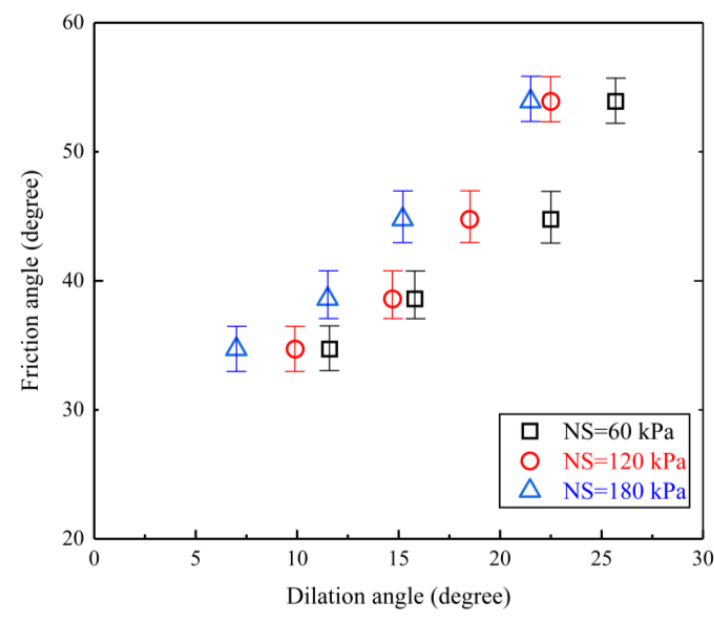

Fig. 10: Friction angle versus dilation angle of sands.

The effect of various soil particle variables on their friction angles was evaluated using nonlinear regression analysis. Table 2 presents the relationship between the sands' friction angle and their particle characteristics. Between the soil uniformity coefficient, $D_{50}$, and their friction angle, it found a power function with a decent coefficient of determination. As presented in the table, the relationship between friction angle and $C U$ has the highest coefficient of de- termination. As a result, $D_{50}$ and $C U$ of soil can be used to estimate the soil's friction angle.
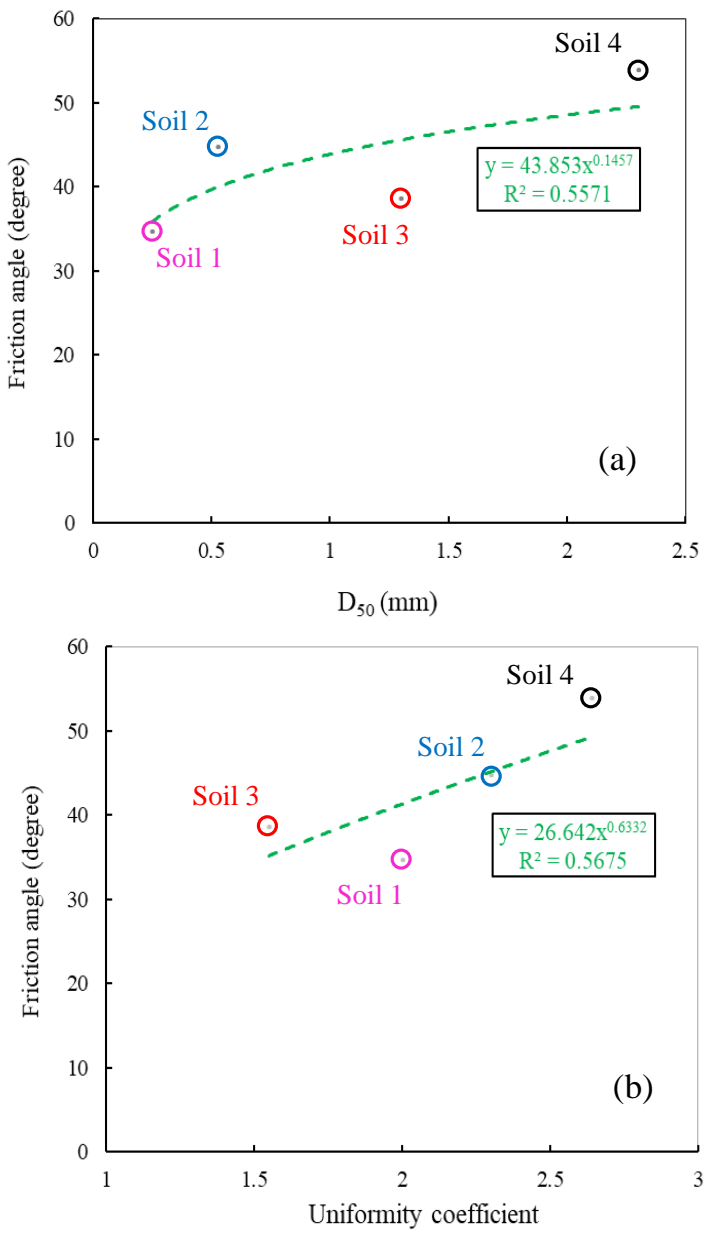

Fig. 11: (a) Friction angle $-D_{50}$ for sands; (b) Friction angle - Uniformity coefficient $(C U)$ for sands.

From Fig. 11, we can see that friction angle increases with increasing the $D_{50}$ and uniformity coefficient. These results seem to be consistent with other research (e.g. Rasti et al. (2021)) which found that soils with bigger $D_{50}$ and uniformity coefficients have higher friction angles. However, soil 3 gives a lower friction angle than soil 2; a possible explanation for this might be that the average data used in this study. Another possible explanation for this is the shape of grains which can influence the friction angle, and didn't consider in this study. 
Tab. 2: Proposed relation between the friction angle and soil particle characteristics.

\begin{tabular}{|l|l|l|l|}
\hline Dependent variable & Independent variable & Proposed equation & $R^{2}$ \\
\hline Friction angle & $\begin{array}{l}\text { Median diameter or medium } \\
\text { value of particle size distribu- } \\
\text { tion }\left(D_{50}\right)\end{array}$ & $43.85 *\left(D_{50}\right)^{0.145}$ & 0.56 \\
\cline { 2 - 4 } & Uniformity coefficient $(C U)$ & $26.64 *(C U)^{0.633}$ & 0.57 \\
\hline
\end{tabular}

\section{Conclusion}

The present study was designed to determine the effect of $D_{50}$ s and particle size distributions on the deformation and shear strength characteristics of four sandy soils. This research has found that generally friction angle of soil is affected by the presence of coarse-grained materials and their particle size distributions. The results of this investigation show that friction and dilation angles of soils will increase with increasing $D_{50} \mathrm{~s}$. It also was concluded that there is a relationship between friction angle and a soil's uniformity coefficient. One of the more significant findings to emerge from this study is that the friction angle increases by increasing the uniformity coefficient. Since the study was limited to poorly graded sands, it is impossible to extend all of the results to all soils. Further research needs to examine more closely the links between particle size distribution of soils and their shear behaviors, especially on the clayey soils.

\section{References}

[1] Gan, J., Fredlund, D., \& Rahardjo, H. (1988). Determination of the shear strength parameters of an unsaturated soil using the direct shear test. Canadian Geotechnical Journal, 25(3), 500-510.

[2] Wen-Jie, X., Qiang, X., \& Rui-Lin, H. (2011). Study on the shear strength of soilrock mixture by large scale direct shear test. International Journal of Rock Mechanics and Mining Sciences, 48(8), 1235-1247.

[3] Afrazi, M., et al. (2018). Numerical analysis of effective parameters in direct shear test by hybrid discrete-finite element method.
Modares Civil Engineering journal, 18(3), 13-24.

[4] Rouhanifar, S., \& M. Afrazi, (2019). Experimental study on mechanical behavior of sand-rubber mixtures. Modares Civil Engineering journal, 19(4), 83-96.

[5] Afrazi, M., Yazdani, M., \& A. Fakhimi. (2017). The numerical study of effect of an oversize particle on the shear strength of sand in direct shear test. 4th international conference on recent innovations in civil engineering, architecture, and urban palnning.

[6] Yazdani, M., et al. (2013). Application of Taguchi method and genetic algorithm for calibration of soil constitutive models. Journal of Applied Mathematics.

[7] Afrazi, M. (2018). Numerical simulation of soil lateral pressure on flexible retaining walls using a hybrid discrete-finite element method. Civil and Environmental Engineering.

[8] Fragaszy, R.J., Su, W., \& Siddiqi, F.H. (1990). Effects of oversize particles on the density of clean granular soils. Geotechnical Testing Journal, 13(2), 106-114.

[9] Fragaszy, R.J., et al. (1992). Modeling strength of sandy gravel. Journal of Geotechnical Engineering, 118(6), 920-935.

[10] Evans, M.D., \& Zhou, S. (1995). Liquefaction behavior of sand-gravel composites. Journal of Geotechnical Engineering, $121(3), 287-298$.

[11] Yagiz, S. (2001). Brief note on the influence of shape and percentage of gravel on the shear strength of sand and gravel mixtures. Bulletin of Engineering Geology the Environment, 60(4), 321-323. 
[12] Vallejo, L.E. (2001). Interpretation of the limits in shear strength in binary granular mixtures. Canadian Geotechnical Journal, 38(5), 1097-1104.

[13] Kokusho, T., Hara, T., \& Hiraoka, R. (2004). Undrained shear strength of granular soils with different particle gradations. Journal of Geotechnical Engineering, 130(6), 621-629.

[14] Hamidi, A., Yazdanjou, V., \& Salimi, N. (2009). Shear strength characteristics of sand-gravel mixtures. International Journal of Geotechnical Engineering, 3(1), 29-38.

[15] Hamidi, A., Alizadeh, and Soleimani, S. (2009). Effect of particle crushing on shear strength a M.nd dilation characteristics of sand-gravel mixtures. International Journal of Civil Engineering, 7(1), 61-71.

[16] Wang, J.-J., et al. (2013). Effects of particle size distribution on shear strength of accumulation soil. Journal of Geotechnical and Geoenvironmental Engineering, 139(11), 1994-1997.

[17] Kuenza, K., et al. (2004). Undrained torsional shear tests on gravelly soils. Landslides, $1(3), 185-194$.

[18] Haeri, S.M., \& Hamidi, A. (2005). Steady state and liquefaction characteristics of gravely sands. Geotechnical \& Geological Engineering, 23(2), 141.

[19] Ghanbari, A., et al. (2008). An experimental study on the behavior of rockfill materials using large scale tests. Electronic Journal of Geotechnical Engineering, 13(Bundle G), 1-16.

[20] Bareither, C.A., Benson, C.H., \& Edil, T.B. (2008). Comparison of shear strength of sand backfills measured in small-scale and large-scale direct shear tests. Canadian Geotechnical Journal, 45(9), 1224-1236.

[21] Bagherzadeh-Khalkhali, A., \& Mirghasemi, A.A. (2009). Numerical and experimental direct shear tests for coarse-grained soils. Particuology, 7(1), 83-91.
[22] Aghaei, A.A., Soroush, A., \& Reyhani, M. (2010). Large-scale triaxial testing and numerical modeling of rounded and angular rockfill materials.

[23] Aghaei, A.A., et al. (2010). Dynamic properties of gravelly materials.

[24] (B,). Seif El Dine, et al. (2010). Mechanical characterization of matrix coarsegrained soils with a large-sized triaxial device. Canadian Geotechnical Journal, $47(4), 425-438$.

[25] Simoni, A., \& Houlsby, G.T. (2006). The direct shear strength and dilatancy of sandgravel mixtures. Geotechnical \&5 Geological Engineering, 24(3), 523-549.

[26] Salimi, N., Yazdanjou, V., \& Hamidi. A. (2008). Shape and size effects of gravel grains on the shear behavior of sandy soils. Proceedings of the 10th International Symposium on Landslides and Engineered Slopes.

[27] Hamidi, A., Azini, E., \& Masoudi, B. (2012). Impact of gradation on the shear strength-dilation behavior of well graded sand-gravel mixtures. Scientia Iranica, 19(3), 393-402.

[28] Rasti, A., et al. (2021). Evaluating the Effect of Soil Particle Characterization on Internal Friction Angle. American Journal of Engineering and Applied Sciences.

[29] Majedi, M.R., Afrazi, M., \& Fakhimi, A. (2021). A micromechanical model for simulation of rock failure under high strain rate loading. International Journal of Civil Engineering, $19(5), 501-515$.

[30] Majedi, M.R., Afrazi, M., \& Fakhimi, A. (2020). FEM-BPM simulation of SHPB testing for measurement of rock tensile strength. in 54th US Rock Mechanics/Geomechanics Symposium. American Rock Mechanics Association.

[31] Sladen, J., et al. (1986). A state parameter for sands-discussion. Géotechnique, 36(1), 123-132. 
[32] Bareither, C.A., et al. (2008). Geological and physical factors affecting the friction angle of compacted sands. Journal of Geotechnical and Geoenvironmental Engineering, 134(10), 1476-1489.

[33] Vermeer, P.A., \& De Borst, R. (1984). Nonassociated plasticity for soils, concrete and rock. Heron, $29(3)$.

[34] Roscoe, K.H., (1970). The influence of strains in soil mechanics. Geotechnique, 20(2), 129-170.

[35] Rouhanifar, S., et al. (2020). Strength and deformation behaviour of sand-rubber mixture. International Journal of Geotechnical Engineering, 1-15.

\section{About Authors}

Mohammad AFRAZI is a research assistant at Tarbiat Modares University. He holds a BSCE and MSCE from Shiraz University and Tarbiat Modares University, respectively.

Mahmoud YAZDANI received his $\mathrm{PhD}$ from Department of Civil and Environmental Engineering, University of Tokyo, Japan, in 2002. He is an assistant professor of geotechnical engineering in the School of Civil and Environmental Engineering, Tarbiat Modares University. 